\title{
Changes in the Major Free Fatty Acids in Serra Cheese Throughout Ripening
}

\author{
Angela C. Macedo \& F. Xavier Malcata* \\ Escola Superior de Biotecnologia, Universidade Católica Portuguesa, Rua Dr António \\ Bernardino de Almeida, 4200 Porto, Portugal
}

\begin{abstract}
Changes in the concentrations of the free fatty acids (FFA) containing an even number of carbon atoms in Serra cheese were monitored using a two-way factorial design over a ripening period of 35 days throughout the cheesemaking season. Both time variables had statistically significant effects at the 5\% level on the concentrations of FFA. The concentration of stearic acid increased significantly to $351 \mathrm{mg}$ $\mathrm{kg}^{-1}$ (fat basis) only during the first week of ripening. Concentrations of palmitic and oleic acids increased significantly during all stages of ripening and approximately doubled during the 35-day ripening period to reach levels of 425 and $453 \mathrm{mg}$ $\mathrm{kg}^{-1}$, respectively. Concentrations of butyric, caprylic, lauric and myristic acids were approximately constant during the first week and increased significantly thercafter up to $285,17,94$ and $59 \mathrm{mg} \mathrm{kg}{ }^{-1}$, respectively, at 35 days. The concentrations of caprylic and myristic acids increased five-fold in 35 days, the concentration of butyric acid increased three-fold, and the concentration of lauric acid almost doubled during the same period. The concentrations of caproic, capric, linoleic and linolenic acids increased significantly to $48,121,188$ and $126 \mathrm{mg} \mathrm{kg} \mathrm{g}^{-1}$, respectively, only after 21 days of ripening. The concentration of linoleic acid doubled in that time period, while increases in the concentrations of caproic, capric and linolenic acids were much smaller. The concentrations of butyric, caproic and palmitic acids in cheeses manufactured in February were statistically lower than those in cheeses manufactured in May. The principal FFAs throughout ripening were, according to chain length and degree of saturation, butyric (short-chain), capric (medium-chain), palmitic and stearic acids (saturated long-chain), and oleic (unsaturated long-chain). Saturated and unsaturated long-chain FFA were present at the highest concentration at all stages of ripening. It is concluded that lipolysis in Serra cheese proceeds slowly to total FFA concentration of $2167 \mathrm{mg} \mathrm{kg}^{-1}$ (fat basis) by 35 days of ripening. Copyright (C) 1996 Elsevier Science Limited
\end{abstract}

*Author to whom correspondence should be addressed. 


\section{INTRODUCTION}

Serra da Estrela (or simply Serra) cheese is probably the most popular variety of traditional cheese in Portugal. It is manufactured at the farmhouse level only, from raw ovine milk of local herds. Coagulation is brought about by a plant rennet (thistle flower) at ca. $28^{\circ} \mathrm{C}$ for $60 \mathrm{~min}$; the coagulum is cut manually to irregularly-shaped small pieces; moulding is achieved via use of cylindrical moulds (ca. $20 \mathrm{~cm}$ wide and $10 \mathrm{~cm}$ high); the curds may or may not be pressed. Salt is added to milk prior to coagulation and/or rubbed on the surface of fresh cheese. Ripening is often carried out for at least 35 days in rooms without any form of temperature or humidity control (average temperature ranges from $8^{\circ} \mathrm{C}$ in November to $4^{\circ} \mathrm{C}$ in February and $16^{\circ} \mathrm{C}$ in May, and average relative humidity ranges from $85 \%$ in November to $95 \%$ in February and to $75 \%$ in May); however, Serra cheese is not usually consumed before 45 days. Macedo et al. (1993) discussed the difficulties arising from the lack of standardization of Serra cheesemaking and attempted to overcome this situation via studies encompassing variations in the microflora of Serra cheese during ripening and throughout the cheesemaking season (Macedo et al., 1995, 1996). Preliminary work on the characterization of lipolysis in such ovine milk cheese was undertaken by Hiscox et al. (1941), who reported that the concentration of volatile acids in the fat fraction of Serra cheese is about $50 \%$ that in Roquefort cheese, Vieira de Sá et al. (1970), who concluded that the perceived quality of Serra and Serpa cheeses is higher when higher concentrations of volatile free fatty acids (especially butyric) are present, and Partidário et al. (1995), who attempted to determine the free fatty acids profile in ovine raw milk coagulated by thistle rennet in the presence of an added starter culture. Conversely, a number of workers have been rather active in detailed studies on the free fatty acid content of Spanish cheeses manufactured from ovine milk (e.g. Gómez et al., 1987; Fuente et al., 1993; Fontecha et al., 1994).

It is widely accepted that several free fatty acids contribute directly to the final flavour characteristics of many types of cheese or indirectly by serving as precursors of such aroma components as ketones (Forss, 1979); however, the relation between total free fatty acid composition and final cheese flavour is still not completely established (Anon., 1991). Although the appearance of free fatty acids in such a complex system as cheese should in general be considered as the net result of several possible processes (e.g. enzymatic hydrolysis of existing glycerides, de novo biosynthesis effected by the microflora and nonenzymatic oxidation of long and/or unsaturated fatty acids), the hydrolytic action of lipases is probably the main route for the formation of free fatty acids especially because of the normal pH range of cheeses (Bills et al., 1969). Lipolytic activity in cheese is well documented (Albrecht \& Jaynes, 1955), and it is known that lipases in cheese may originate from the milk, from the indigenous (or added) microorganisms (Stead, 1986), and possibly from rennet. Furthermore, the relative proportions of free fatty acids in cheese are expected to depend on the seasonal composition of the milk (which in turn results from the animals' feed and physiological condition) and on the relative activity of lipases in the cheese (Anon., 1991).

The aim of the present work was to determine the profile of the major free fatty acids in Serra cheese throughout ripening and throughout the cheesemaking season. The motivation for this work was the realization that such profiling 
should allow a preliminary evaluation of the significance of lipolysis in Serra cheese, which may eventually serve as a basis for understanding flavour defects in this ancient, gourmet-type food, and ultimately contribute to the goal of standardizing the cheesemaking process.

\section{MATERIALS AND METHODS}

\section{Cheese manufacture and sampling}

Three batches of twelve $0.5 \mathrm{~kg}$ cheeses were prepared following the traditional cheesemaking protocol (Macedo et al., 1993) in a selected dairy farm located in the region possessing the Appéllation Serra Controllée status; these batches were prepared at three periods during the cheesemaking season, i.e. November, February and May. These three periods were chosen in order to be as representative as possible of the different periods in the lactation season in terms of animal feed, animal physiological state and environmental conditions (which are determined mainly by the local weather).

Three cheeses from each batch were selected randomly during the ripening period after $0,7,21$ and 35 days and transported under refrigerated conditions (ca. $4^{\circ} \mathrm{C}$ ) to our laboratory. Each sample of cheese was prepared by homogenizing the cheese after the rind had been carefully removed, and freezing at $-30^{\circ} \mathrm{C}$ in Whirl-pak vacuum packages (Cole-Parmer, Chicago, IL, USA) until analysed.

\section{Chemical analyses}

Total fat content in cheese was determined by the Gerber-Van Gulik method (Anon., 1975a, b). For determination of individual free fatty acids, $5 \mathrm{~g}$ of cheese were macerated and carefully mixed with nonanoic and heptadecanoic acids (Sigma, Darmstad, Germany) as internal standards for quantitative determinations, and mixed using a vortex with $2.5 \mathrm{~g}$ of anhydrous $\mathrm{Na}_{2} \mathrm{SO}_{4}$ (Merck) and 10 $\mathrm{mL}$ of HPLC-grade diethyl ether (Merck) in a screw-capped bottle. The mixture was then stirred in the vortex for $1 \mathrm{~min}$ every $1 \mathrm{~h}$ for a total of $4 \mathrm{~h}$, and homogenized in a Sonorex RK100 (Bandelin, Berlin, Germany) for 15 min every $1.5 \mathrm{~h}$ over the same period. The concentration of free fatty acids in the diethyl ether extracts was determined by HPLC using the method by Garcia et al. (1990). Separation was achieved using a C-18 Reverse Phase column (4.6 mm I.D. $\times 250$ $\mathrm{mm}$ length) of Ultrasphere $(\mathrm{M})$ with a particle diameter of $5 \mu \mathrm{m}$ and an average pore diameter of $80 \AA$ (Beckman, San Ramon CA, USA); resolution was achieved using a solvent delivery system with a dual pump (Beckman Programmable Solvent Module 126) equipped with an autosampler (Beckman Model 502) with a $20-\mu \mathrm{L}$ loop, and using a ternary solvent gradient of methanol, water and acetonitrile (Merck); detection was by spectrophotometry at $254 \mathrm{~nm}$ (Beckman Model 168). System control and data acquisition and handling used the System Gold DV601 (Beckman).

\section{Statistical analyses}

The data were treated using analysis of variance (to assess whether the position within the ripening period and/or within the manufacturing season were statisti- 
cally significant), Fisher's protected least significant difference test (to screen for statistically significant differences between the lipolysis data at various times within the ripening period and within the manufacturing season) and principal components analysis (to detect the maximum number of statistically significant mutual correlations between the data concerning the various free fatty acids, irrespective of position within the ripening period or within the manufacturing season). All analyses used the Statview 4.0 (iil) statistical package (Haycock et al., 1992).

\section{RESULTS AND DISCUSSION}

Analysis of variance of data pertaining to the fat content of Serra cheese, expressed on a dry weight basis, manufactured and ripened at different periods during the cheesemaking season were statistically similar to one another (the probability that such large changes occurred by chance, $P$, was $P=0.291$ ). However, the fat content, on a total weight basis, showed a statistically significant increase with ripening time $(P<0.0001)$ and within the cheesemaking season $(P=0.0078)$. As mentioned elsewhere, the moisture content correlated negatively with the fat content; e.g. the fat content tended to be higher and the moisture content lower in May when the ripening temperature is higher and water lost is also higher than at other periods (Macedo et al., 1996).

The concentrations of free nonanoic (C9:0) and heptadecanoic acids (C17:0) in ovine milk cheeses have been reported to be rather low (Fuente et al., 1993), and often they are not found at all (Gómez et al., 1987; Nágera et al., 1993). Preliminary analyses (not shown) confirmed that these acids existed in Serra cheese at trace levels, and furthermore indicated that the ratio of C17:0 to C9:0 did not change statistically during ripening. Therefore, use of these compounds as internal standards (as done in the present research work) seems safe from an analytical point of view.

The data obtained for the concentrations (on a fat basis) of individual free fatty acids (FFA) throughout the ripening period and throughout the cheesemaking season are tabulated in Table 1. Analysis of variance of all such data indicated that the concentration of each free fatty acid changed during ripening $(P<0.0001)$. The FFA profile in cheese on the day of manufacture showed essentially stearic, palmitic and oleic acids, smaller amounts of linoleic, capric, butyric and linolenic acids, and only traces of lauric, caproic, myristic and caprylic acids. Profiles of free fatty acids in ovine milk have been reported by Olmedo \& Coll-Hellin (1976) and Gatusso \& Fazio (1980), who found that palmitic and oleic acids were the predominant FFAs in milk whereas caproic, caprylic, linoleic and linolenic acids were present at lowest concentrations. Our analyses indicated that after 35 days of ripening, Serra cheese had high concentrations of oleic, palmitic, stearic and butyric acids, intermediate concentrations of linoleic, linolenic, capric and lauric acids, and low concentrations of myristic, caproic and caprylic acids; the behaviour was similar throughout the cheesemaking season. These observations agree with those by Olmedo \& Coll-Hellin (1976) for Spanish ovine milk cheeses and those by Gattuso \& Fazio (1980) for Italian ovine milk cheeses. Therefore, the highest fold increases were observed for myristic, caprylic and butyric acids (mean values of ca. 5.2, 5.2 and 3.4, respectively) after 35 days. These results are consistent with the fact that lipases (originating mainly in milk and microorganisms) involved in cheese ripening 


\section{TABLE 1}

Changes in the concentration ( $\mathrm{mg} \mathrm{kg}^{-1}$ fat), and associated standard error, of free fatty acids in Serra cheese during ripening and at different periods within the cheesemaking season: November (1st row), February (2nd row) and May (3rd row).

\begin{tabular}{|c|c|c|c|c|}
\hline \multirow[b]{2}{*}{ Free fatty acid } & \multicolumn{4}{|c|}{ ripening time (days) } \\
\hline & 0 & 7 & 21 & 35 \\
\hline \multirow[t]{3}{*}{ butyric (C4:0) } & $910 \pm 14$ & $1132 \pm 41$ & $2398 \pm 275$ & $3202 \pm 187$ \\
\hline & $868 \pm 50$ & $936 \pm 43$ & $2543 \pm 237$ & $2375 \pm 38$ \\
\hline & $764 \pm 34$ & $865 \pm 17$ & $1620 \pm 85$ & $2984 \pm 111$ \\
\hline \multirow[t]{3}{*}{ caproic (C6:0) } & $447 \pm 29$ & $388 \pm 20$ & $396 \pm 24$ & $398 \pm 02$ \\
\hline & $422 \pm 07$ & $390 \pm 52$ & $394 \pm 34$ & $474 \pm 13$ \\
\hline & $359 \pm 28$ & $342 \pm 23$ & $358 \pm 09$ & $566 \pm 46$ \\
\hline \multirow[t]{3}{*}{ caprylic (C8:0) } & $50 \pm 12$ & $26 \pm 01$ & $149 \pm 12$ & $138 \pm 05$ \\
\hline & $34 \pm 17$ & $83 \pm 33$ & $69 \pm 22$ & $170 \pm 13$ \\
\hline & $16 \pm 07$ & $33 \pm 12$ & $74 \pm 11$ & $206 \pm 40$ \\
\hline \multirow[t]{3}{*}{ capric $(\mathrm{C} 10: 0)$} & $1156 \pm 41$ & $912 \pm 46$ & $1023 \pm 99$ & $1016 \pm 86$ \\
\hline & $893 \pm 05$ & $1005 \pm 111$ & $963 \pm 74$ & $1217 \pm 65$ \\
\hline & $916 \pm 36$ & $868 \pm 67$ & $887 \pm 31$ & $1397 \pm 210$ \\
\hline \multirow[t]{3}{*}{ lauric (C12:0) } & $569 \pm 25$ & $543 \pm 13$ & $765 \pm 107$ & $791 \pm 106$ \\
\hline & $513 \pm 16$ & $580 \pm 72$ & $679 \pm 25$ & $927 \pm 55$ \\
\hline & $468 \pm 12$ & $553 \pm 38$ & $654 \pm 42$ & $1090 \pm 202$ \\
\hline \multirow[t]{3}{*}{ myristic (C14:0) } & $120 \pm 44$ & $144 \pm 19$ & $606 \pm 79$ & $716 \pm 52$ \\
\hline & $126 \pm 25$ & $170 \pm 85$ & $270 \pm 39$ & $512 \pm 76$ \\
\hline & $95 \pm 20$ & $180 \pm 60$ & $316 \pm 40$ & $529 \pm 35$ \\
\hline \multirow[t]{3}{*}{ palmitic (C16:0) } & $2733 \pm 391$ & $3177 \pm 98$ & $3167 \pm 403$ & $4141 \pm 218$ \\
\hline & $2412 \pm 97$ & $3305 \pm 367$ & $3499 \pm 168$ & $3538 \pm 197$ \\
\hline & $2092 \pm 50$ & $3064 \pm 442$ & $3412 \pm 461$ & $5070 \pm 253$ \\
\hline \multirow[t]{3}{*}{ stearic (Cl8:0) } & $3298 \pm 258$ & $3379 \pm 71$ & $3294 \pm 184$ & $3426 \pm 60$ \\
\hline & $2763 \pm 88$ & $3484 \pm 375$ & $3318 \pm 282$ & $3109 \pm 129$ \\
\hline & $2467 \pm 64$ & $3081 \pm 327$ & $3355 \pm 402$ & $4008 \pm 522$ \\
\hline \multirow[t]{3}{*}{ oleic (C18:1) } & $2243 \pm 224$ & $2767 \pm 472$ & $2801 \pm 212$ & $4137 \pm 599$ \\
\hline & $1746 \pm 79$ & $2147 \pm 330$ & $2547 \pm 117$ & $4477 \pm 321$ \\
\hline & $1571 \pm 124$ & $2556 \pm 47$ & $3285 \pm 274$ & $4966 \pm 564$ \\
\hline \multirow[t]{3}{*}{ linoleic (C18:2) } & $956 \pm 11$ & $1185 \pm 104$ & $1348 \pm 187$ & $1388 \pm 112$ \\
\hline & $732 \pm 14$ & $932 \pm 85$ & $1006 \pm 32$ & $1703 \pm 103$ \\
\hline & $789 \pm 58$ & $1206 \pm 45$ & $1819 \pm 326$ & $2550 \pm 848$ \\
\hline \multirow[t]{3}{*}{ linolenic (C18:3) } & $1317 \pm 32$ & $1122 \pm 37$ & $1113 \pm 52$ & $1076 \pm 32$ \\
\hline & $1171 \pm 15$ & $1095 \pm 44$ & $1020 \pm 39$ & $1273 \pm 33$ \\
\hline & $1100 \pm 39$ & $1131 \pm 71$ & $1187 \pm 26$ & $1421 \pm 154$ \\
\hline
\end{tabular}


preferentially hydrolyse short- and medium-chain fatty acid residues since these acids predominate at the $s n-3$ position (Fuente $e t$ al., 1993). The fold increases for oleic, linoleic, lauric and palmitic acids were $2.5,2.3,1.8$ and 1.8, respectively, and for capric, stearic and caproic acids were ca. 1.2. Very little linolenic acid was released during ripening (fold increase of ca. 1.1). Our results were similar to those reported by Nájera et al. (1994) for Idiazabal cheese of the same age except for palmitic acid (which was extensively released).

Fisher's protected least significant difference tests indicated that: (i) the concentrations of butyric, caprylic, lauric and myristic acids remained approximately constant in cheese during the first week of ripening, but increased significantly therafter up to 35 days; (ii) the concentrations of caproic, capric, linoleic and linolenic acids did not increase significantly until 21 days of ripening; (iii) the concentration of stearic acid increased considerably during the first week and then levelled off; and (iv) the concentrations of palmitic and oleic acids increased throughout the ripening period. Although lactococci possess low lipolytic activity, they can hydrolyse milk fat to a significant extent during cheese ripening if present at high numbers and in the absence of a strongly lipolytic surface microflora (Fryer et al., 1967; Stadhouders \& Veringa, 1973). Singh et al. (1973) found that Lactococcus spp. were more active on tributyrin than on tripalmitate or triolein, while Kamaly et al. (1988) observed that lipases in cell-free extracts of a number of strains of Lactococcus were more active on triglycerides containing short-chain (C4:0-C10:0) than medium and long-chain (C12:0-C18:0) fatty acid residues. Psychrothrophs are potentially important sources of active lipases in cheese if their numbers exceed $10^{6} \mathrm{cfu} \mathrm{\textrm {mL } ^ { - 1 }}$ in refrigerated milk (Cousins et al., 1977; Juven et al., 1981). Macedo et al. $(1995,1996)$ reported that lactic acid bacteria and Enterobacteriaceae reach their maximum numbers (ca. $10^{7}$ and $10^{6}$ cfu $\mathrm{g}^{-1}$, respectively) after the first week of ripening, Lactococcus lactis and Leuconostoc lactis are the predominant lactic acid bacteria, and Hafnia alvei (psychrothropic bacterium) is the predominant Enterobacteriaceae in Serra cheese during ripening. Therefore, most short- and medium-chain chain FFA were not initially hydrolyzed probably because the lactic acid bacteria did not yet exist in sufficiently high numbers to display detectable lipolytic activity (although actual assays of lipolytic activity in pure strains of lactic acid bacteria were not performed). The release of palmitic, stearic and oleic acids was considerable during the initial stages of ripening, probably because the indigenous lipase in milk from small ruminants (which has not been fully characterized to date) (i) acts like its bovine milk counterpart in terms of activity, i.e. it exhibits significant lipolytic activity only during early stages of ripening, but (ii) acts differently from the bovine milk counterpart in terms of selectivity, i.e. it tends to liberate fatty acids from the $s n-1$ and $s n-3$ positions (rather than just from the $s n-3$ position) of mono-, di-, and triglycerides of milkfat (Madkor \& Fox, 1987). The plant rennet (thistle flower) used to manufacture Serra cheese has not been characterized to date in terms of lipolytic activity; however, it is apparently responsible for a minor contribution to the release of FFA compared with the contribution in some Italian cheeses where lipases are deliberately included in the rennet preparation. This observation suggests that the aforementioned plant rennet deserves further consideration because good quality (animal) rennets are virtually free of lipolytic activity (Fox et al., 1995).

Traditionally, discussion of lipolysis in cheeses is based upon actual measured concentrations of free fatty acids at a given ripening time (which are an indication 
of the extent of lipolysis); however, further useful information on the activity of lipases may be obtained if the actual rate of release of FFA (estimated as the ratio of the amount of fatty acids released in a given time period divided by such time period) is considered rather than the integrated (or cumulative) result thercof. The behaviour was similar throughout the cheesemaking season; average rates of release of palmitic (110), oleic (91), stearic (68) and linoleic $\left(40 \mathrm{mg} \mathrm{kg}^{-1} \mathrm{day}^{-1}\right.$ ) acids were highest prior to 7 days of ripening compared with the average rates for the remaining FFA (below $19 \mathrm{mg} \mathrm{kg}^{-1} \mathrm{day}^{-1}$ ). Between 7 and 21 days, the highest rate of hydrolysis was for butyric (86), followed by oleic (28), linoleic (20) and myristic (17 mg kg${ }^{-1}$ day $^{-1}$ ) acids, while the concentrations of the remaining acids increased slowly (at rates below $12 \mathrm{mg} \mathrm{kg}^{-1}$ day $^{-1}$ ). Between 21 and 35 days of ripening, oleic acid was released at the highest rate (118), followed by palmitic (64), butyric (48) and linoleic ( $35 \mathrm{mg} \mathrm{kg}^{-1} \mathrm{day}^{-1}$ ), whereas the remaining fatty acids were released at rates below $18 \mathrm{mg} \mathrm{kg}^{-1}$ day $^{-1}$. Nájera et al. (1994) reported that in Idiazabal ovine milk cheese, with a similar ripening time, butyric and palmitic acids are released at the highest rates.

The period within the cheesemaking season had no statistical effect on the concentrations of caprylic, myristic and palmitic acids in 0 day-old cheeses. However, the concentrations of butyric, caproic, lauric and stearic in 0 day-old cheeses manufactured in November (see Table 1) were significantly higher at the $5 \%$ level of significance than those in cheeses manufactured in May, but statistically similar to those in cheeses manufactured in February. Additionally, the concentrations of capric, linoleic and linolenic acids in 0 day-old cheese manufactured in November (see Table 1) were significantly higher $(P<0.05)$ than those manufactured in May or February, which were statistically similar. The FFA composition of cheese on the day of manufacture depends essentially on the FFA composition of milk which is in turn largely dependent on the type of animal feed, the prevailing weather and the physiological conditions (which depend on the stage of lactation, the age of the animal and its genetic uniqueness) (Nágera $e t$ al., 1993). Considering that the same breed was used (Bordaleira da Serra da Estrela) as well as the same flock, it appears that the local weather, animal feeding and the period of lactation (typically lactation starts in October and ends in June) should be the major factors responsible for the observed variations of FFA concentrations among the 0 day-old cheeses manufactured in different months. After 35 days of ripening, cheese manufactured in May or November had significantly higher concentrations of butyric acid (see Table 1) than cheeses manufactured in February. For the same length of ripening (35 days), cheeses manufactured in May had significantly higher concentrations of caproic and palmitic acids than cheeses manufactured in November or February, which were statistically similar. Concentrations of the remaining FFA in 35 day-old cheeses did not show statistically significant differences throughout the cheesemaking season. These differences of FFA concentrations in 35 day-old cheeses throughout the cheesemaking season can in principle be explained by different initial content of individual FFA, microbial profile (which can affect the intrinsic characteristics of lipases), and ripening temperature, $\mathrm{pH}$ and salt and moisture contents (which can affect the activity of lipases). Considering that, in general, after 35 days of ripening, cheeses manufactured in May had statistically higher concentrations of FFA than those manufactured in November or February, it appears that the $\mathrm{pH}$ and ripening temperature are factors that may influence significantly lipase activity. This is so because the ripening temperature in May is 
higher, on average, than during the other two months due to average higher ambient temperatures; Nuñez et al. (1986) reported that increases of 5 to $10^{\circ} \mathrm{C}$ in the ripening temperature (usually ca. $10^{\circ} \mathrm{C}$ ) led to increases of $24-70 \%$ in FFA concentrations in 60-day old cheese; on the other hand, the $\mathrm{pH}$ in Serra cheese tended to be statistically higher in May than in November or February (Macedo et al., 1996). Considering that FFA concentrations in cheese on the day of manufacture were highest in November and lowest in May (as discussed before), it appears that the initial FFA composition in cheese did not significantly influence hydrolysis. Conversely, Macedo et al. $(1995,1996)$ reported that lactoccocci numbers were highest in February and lowest in May, but the numbers of Enterobacteriaceae were highest in May and lowest in February: hence, the microbial profile could significantly affect the hydrolysis of fatty acid residues.

The overall FFA concentration for 35 day-old Serra cheese $\left(2167 \mathrm{mg} \mathrm{kg}^{-1}\right)$ was lower than that reported by Fuente et al. (1993) for the ovine milk cheeses Roncal, Manchego and Idiazabal. The low FFA content in Serra cheese was expected because it is a short ripened cheese compared to the above mentioned cheeses. Using the data in Table 1, it is concluded that the long-chain saturated (i.e. C16:0 and C18:0) and long chain unsatured (C18:1, C18:2 and C18:3) FFA were the most abundant acids at all stages of ripening. Similar results have been reported for other types of ovine milk cheeses such as Idiazabal (Fuente $e t$ al., 1993; Nágera et al., 1994), Roncal (Gómez et al., 1987; Fuente et al., 1993) and Majorero (Fuente et al., 1993). Use of principal components analysis to assess the degree of correlation between the concentrations of the various free fatty acids found in Serra indicated that no apparent clusters exist (see Fig. 1), although

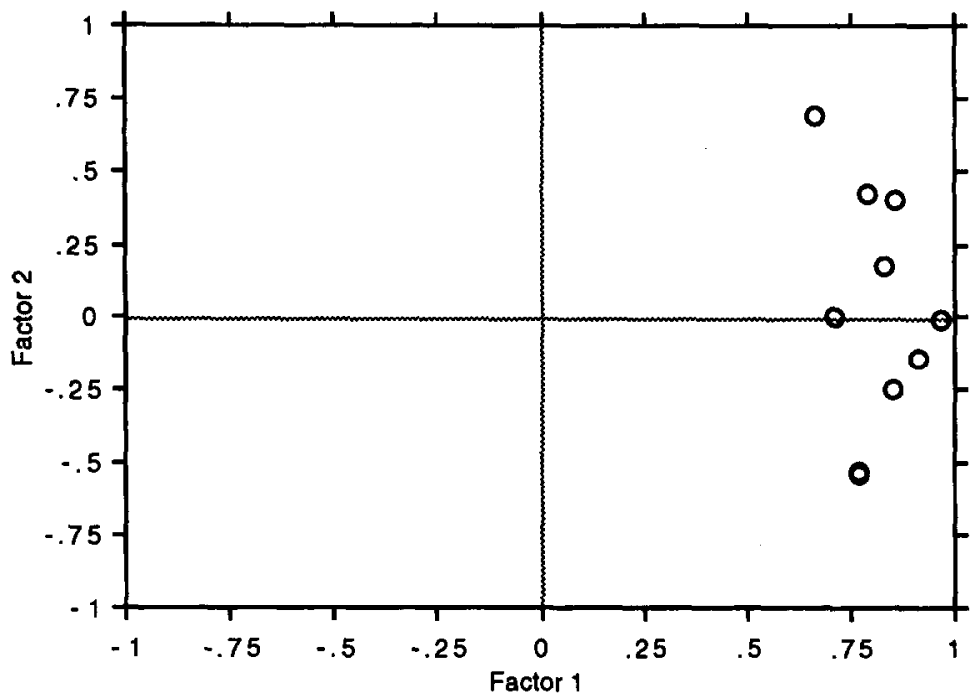

Fig. 1. Plot of the unrotated two-factor solution obtained from principal components analysis using all data generated on the various concentrations of free fatty acids (from top to bottom: C18:3, C6:0, C10:0, C18:2, C18:0, C12:0, C18:1, C8:0, C16:0, C14:0, C4:0). Eigenvalues: 7.510 and 1.506; eigenvectors: -0.281 and -0.436 (C4:0), -0.288 and 0.340 (C6:0), -0.333 and -0.115 (C8:0), -0.313 and 0.325 (C10:0), -0.353 and $-0.004(\mathrm{C} 12: 0),-0.282$ and -0.427 (C14:0), -0.311 and $-0.200(\mathrm{C} 16: 0),-0.259$ and $0.006(\mathrm{C} 18: 0),-0.333$ and -0.111 (C18:1), -0.303 and $0.146(\mathrm{C} 18: 2)$, and -0.242 and 0.565 (C18:3). 
C8:0, C12:0, C18:0, C18:1 and C18:2 can be tentatively considered as part of a group (with somewhat similar characteristics) denoted as factor 1 .

Despite their relatively high concentrations, myristic and longer chain FFA do not contribute to cheese flavour nearly as much as short chain (i.e. C4:0, C6:0 and C8:0) FFA do (Baldwin et al., 1973). Fuente et al. (1993) correlated the high levels of short chain FFA with the strong and sharp flavour of the ovine milk cheese studied: a soapy flavour correlated well with the presence of free capric and lauric acids (Anon., 1991). At full maturity, Serra cheese has higher levels of caprylic acid than bovine milk cheeses, which may be responsible for a certain degree of goat-like flavour (Woo et al., 1984). The data generated in this study have shown that butyric and capric acids were the most concentrated short chain and medium chain (i.e. C10:0, C12:0 and C14:0) FFAs, respectively, in 35 day-old Serra cheese. Additionally, the concentrations of palmitic and stearic acids were similar to one another. Oleic acid was the dominant long chain unsaturated FFA. In such Spanish cheeses as Idiazabal, Majorero and Roncal, butyric and palmitic acids were the most concentrated short chain and long chain FFA, respectively (Gómez et al., 1987; Fuente et al., 1993; Nájera et al., 1994). Although Nájera et al. (1994) reported that capric acid was the dominant medium chain FFA, Fuente et al. (1993) observed higher concentrations of myristic acid than capric acid; these researchers also reported that oleic acid was the most concentrated long chain unsaturated FFA.

As in Manchego (Ramos \& Martínez Castro, 1976) and Serena cheese (Fernández del Pozo et al., 1988), lipolysis in Serra cheese proceeds slowly; in addition to the short ripening time, the fact that lipases (or esterases) are not deliberately added as such (unlike typical Italian cheese varieties) and are not produced by deliberately added mould adjunct starters (unlike mould-ripened cheese varieties) have been implicated in attempts to explain this observation (Bills et al., 1969; Fernández-Salguero et al., 1986). Ha \& Lindsay (1990) reported that in ruminant milk fat, the flavour thresholds of the lower even carbonnumbered FFA are only a few $\mathrm{mg} \mathrm{kg}^{-1}$ and the flavour threshold increases with the chain length of the fatty acid; hence, although the concentrations of short and medium chain FFA in Serra cheese at 35 days of ripening are relatively low, they are likely to contribute subtle key notes to the flavour characteristics of this longcelebrated cheese

\section{ACKNOWLEDGEMENTS}

The authors are grateful to the members of the technical board of ANCOSE (the National Portuguese Breeders Association of Serra da Estrela Sheep) for their cooperation encompassing the local manufacture and transport of cheeses. Financial support for author A. C. Macedo was provided by a Ph.D. fellowship (CIENCIA BD-1741/91-IF). Financial support for the research work was partly obtained via project grants MAQUETTE: Improvement of traditional cheeses and their technology (AI, Portugal) and Design and production of an enzymatic and microbial mixture to improve the process ewe's cheese (Spain, France, Italy and Portugal) safety and quality and to get a novel functional food as a response to European demand for new products low in cholesterol and protein enriched (AAIR, EU). 


\section{REFERENCES}

Albrecht, T.W. \& Jaynes, H.O. (1955). Milk lipases. J. Dairy Sci., 38, 137-144.

Anderson, D.F. \& Day, E.A. (1965). Quantitative analysis of the major free fatty acids in Blue cheese. J. Dairy Sci., 48, 248-249.

Anon. (1975a). Fromages. Détermination de la teneur en matière grasse. Butyromètre pour la méthode Van Gulik. Norme Internationale ISO 3432. Nederlands NormalisetieInstitut, Delft, The Netherlands.

Anon. (1975b). Fromages. Détermination de la teneur en matière grasse. Norme Internationale ISO 3433. Nederlands Normalisetie-Institut, Delft, The Netherlands.

Anon. (1991). Determination of free fatty acids in milk and milk products. FIL-IDF Standard 265. International Dairy Federation, Brussels.

Baldwin, R.E., Cloninger, M.R. \& Lindsay, R.C. (1973). Flavor thresholds for fatty acids in buffered solutions. J. Food Sci., 38, 528-530.

Bills, D.D., Scanlan, R.A., Lindsay, R.C. \& Sather, L. (1969). Free fatty acids and the flavor of dairy products. $J$. Dairy $S c i ., 52,1340-1345$.

Cousins, C.M., Sharpe, M.E. \& Law, B.A. (1977). The bacteriological quality of milk for Cheddar cheesemaking. Dairy Ind. Int., 42, 12-18.

Fontecha, J., Pelaez, C. \& Juarez, M. (1994). Biochemical characteristics of a semi-hard ewe's milk cheese. Z. Lebensm. Unter. Forsch., 198, $24-28$.

Fernández del Pozo, B., Gaya, B., Medina, M., Rodríguez-Marín, M.A. \& Nuñez, M. (1988). Changes in chemical and rheological characteristics of La Serena ewe's milk cheese during ripening. J. Dairy Res., 55, 457-464.

Fernández-Salguero, J., Florido, S., Alcalá, M., Marcos, A. \& Esteban, M.A. (1986). Fatty acids composition in some Spanish mold-ripened cheeses. Grasas y Aceites, 3, 152-155.

Forss, D.A. (1979). Review of the Progress of Dairy Science: Mechanisms of formation of aroma compounds in milk and milk products. J. Dairy Res., 46, 691-706.

Fox, P. F., Singh, T. K. \& McSweeney, P. L. H. (1995). Biogenesis of flavor compounds in cheese. In Chemistry of Structure-Function Relationships in Cheese, eds E. L. Malin and M. M. Tunick. Plenum Press, New York, pp. 59-98.

Fryer, T., Reiter, B. \& Lawrence, R.C. (1967). Lipolytic activity of lactic acid bacteria. $J$. Dairy Sci., 50, 7388-394.

Fuente, A.M., Fontecha, J. \& Juárez, M. (1993). Fatty acid composition of the triglyceride and free fatty acid fractions in different cow-, ewe- and goat-milk cheeses. $Z$. Lebensm. Unters. Forsch., 196, 155-185.

Garcia, H., Reyes, H.R., Malcata, F.X., Hill, C.H. \& Amundson, C.H. (1990). Determination of the major free fatty acids in milkfat using a three-component mobile phase for HPLC analysis. Milchwissenschaft, 45, 757-759.

Gatusso, A.M. \& Fazio, G. (1980). Characteristics and composition of milk fat from sheep of Sicilian breeds. Rivista Italiana delle Sostanze Grasse, 57, 530-535.

Gómez, R., Fernández-Salguero, J. \& Marcos, A. (1987). Composición en ácidos grasos libres y combinados de algunas variedades de quesos comerciales. Grasas y Aceites, 38, 23-26.

Ha, J.K. \& Lindsay, R.C. (1990). Method for the quantitative analysis of volatile free and total branched-chain fatty acids in cheese and milk fat. J. Dairy Sci., 73, 1988-1999.

Haycock, K., Roth, J., Gagnon, J., Finzer, W. F. \& Soper, C. (1992). Statview v. 4.0: The Ultimate Integrated Data Analysis and Presentation System. Abacus Concepts: Berkeley, CA, USA.

Hiscox, E.R., Rowland, S.J., Wolf, J. \& Jacob, M. (1941). Nota acerca da bacteriologia e química do queijo português de leite de ovelha (Serra). Bol. Pecu. (Lisb.), 9, 163170.

Juven, B.J., Gordin, S., Rosenthal, I. \& Laufer, A. (1981). Changes in refrigerated milk caused by Enterobacteriaceae. J. Dairy Sci., 64, 1781-1784.

Kamaly, K.M., El-Soda, M. \& Marth, E.H. (1988). Esterolytic activity of Streptococcus lactis, Streptococcus cremoris and their mutants. Milchwissenschaft, 43, 346-351. 
Madkor, S. \& Fox, P.F. (1987). Studies on the ripening of Stilton cheese: lipolysis. Food Chem., 25, 93-109.

Macedo, A., Malcata, F.X. \& Oliveira, J.C. (1993). The technology, chemistry and microbiology of Serra cheese: a review. J. Dairy Sci.. 76, 1725-1739.

Macedo, A.C., Malcata, F.X. \& Hogg, T.A. (1995). Microbiological profile in Serra ewes' cheese during ripening. J. Appl. Bacteriol., 79, 1-11.

Macedo, A.C., Costa, M.L. \& Malcata, F.X. (1996). Characterization of the microflora of Serra cheese: Evolution throughout ripening time, lactation period, and axial location. Int. Dairy J., 6, 79-94.

Nájera, A.I., Barron, L.J.R. \& Barcina, Y. (1993). Review: lipid fraction composition of cow's, sheep's, and goat's cheese, and the influence on its quality. Rev. Esp. Ciencia Tecnol. Alim., 33, 345-363.

Nájera, A.I., Barron, L.J.R. \& Barcina, Y. (1994). Changes in free fatty acids during the ripening of Idiazabal cheese: influence of brining time and smoking. J. Dairy Res., 61, 281-288.

Nuñez, M., García-Aser, C., Rodríguez-Marín, M.A., Medina, M. \& Gaya, P. (1986). The effect of ripening and cooking temperature on proteolysis and lipolysis in Manchego cheese. Food Chem., 21, 115-123.

Olmedo, G.R. \& Coll-Hellin, L. (1976). Contribucton al estudio de la grasa de leche de ovejas españolas. Anales de Bromatologia, 38, 211-340.

Partidário, A. M., Barbosa, M., \& Vilas Boas, L. (1995). Ácidos gordos livres e outros compostos do aroma em queijo de ovelha. Proc. Portuguese Meeting of Food Chemistry, Santarém, Portugal. Paper no. 9.

Ramos, M. \& Martínez Castro, I. (1976). Étude de la protéolyse du fromage type Manchego au cours de l'affinage. Lait, 56, 164-176.

Stadhouders, J. \& Veringa, H.A. (1973). Fat hydrolysis by lactic acid bacteria in cheese. Neth. Milk Dairy J., 27, 77-91.

Stead, D. (1986). Microbial lipases: their characteristics, role in food spoilage and industrial uses. J. Dairy Res., 53, 481-505.

Singh, A., Srinivansan, R.A. \& Dudani, A.T. (1973). Studies on exocellular and endocellular lipases of some lipolytic bacteria. Milchwissenschaft, 28, 164-173.

Vieira de Sá, F., Machado, B.R., Pinto, O.R., Cruz, I.V., Carneiro, M.D., Barbosa, M. \& Reis, M.C. (1970). Maturação em queijos de ovelha Serra e Serpa. In Química e Biologia, 6, 148-152.

Woo, A.H., Kollodge, S. \& Lindsay, R.C. (1984). Quantification of major free fally acids in several cheese varieties. J. Dairy Sci., 67, 874-878. 